\title{
The role of green buildings in supporting green buyer behaviour towards green users
}

\author{
Galuh Talitha Ayuthia ${ }^{1}$, Ova Candra Dewi ${ }^{1 *}$, and Toga H. Panjaitan ${ }^{1}$ \\ ${ }^{1}$ Department of Architecture, Faculty of Engineering, Universitas Indonesia, Depok, 16425, Indonesia
}

\begin{abstract}
This study examines whether green buildings support their users in buying residential property, especially the apartment units. This study aims to determine whether green buildings users practice environmentally friendly aspects of choosing a residential property. This study assumes that green buildings can nurture green users and green users over time, become green buyers. The quantitative approach used to prove how many building users have a better concern for the green environment, and this was done through the Consideration of Future Consequences (CFC) Scale and Parameters of Individual Behaviour towards the Environment (PSTL) through a questionnaire. Two scenarios of property brochures (Green and Non-Green) are also used as research mediums, and written interviews are conducted to find factors that support the user in choosing green residential properties. This research shows a significant influence between green buildings' users and the selection of green residential property by 0.009 . It concludes that the questionnaire's values on all buildings tend to influence or play a role in the user's property selection. Moreover, the percentage of green buildings users who have chosen green property brochures reaches $79.5 \%$ and is higher than the percentage from the users of conventional buildings.
\end{abstract}

\section{Introduction}

In recent years, the concept of green building, which is also known as sustainable building, has become a common interest in various disciplines [1]. Green Building is the practice of designing, constructing, and operating buildings to maximize occupant health and productivity, use fewer resources, reduce waste and negative impacts on the environment, and reduce life-cycle costs [2]. Apart from reducing the environmental impact, one of the main objectives in constructing "green" buildings is to improve the quality of life of its users [3]. The emergence of gaps in green buildings as an effort to minimize environmental impact is not due to the wrong design and technology, but because the behaviour of building users also plays a big role in the success of a green building. "Buildings do not use energy, but people do" [4]. In other words, green buildings also need green users to achieve their sustainability goals.

*Corresponding author : ova.candewi@ui.ac.id 
The green concern is now a subject that constantly changes buyers' behaviour to be more environmentally responsible [5]. As a product buyer, it is necessary to realize that a person's consumption behaviour can make a difference. It also has to appreciate the benefits of products that are more environmentally friendly [6]. For example, buyers in an architectural context in buying a residential property or apartment unit are now also encouraged to prioritize environmentally friendly aspects in choosing it.

Previous research shows a consistency that green buildings can nurture green users, and green users will eventually become green buyers [1]. To find out the consistency of whether these behaviours also apply in green buildings in Indonesia, another view is needed regarding the behaviour that is formed in conventional buildings.

This research focuses on the role of green buildings that support green users' behaviour and green buyers in conventional buildings. It aims to see whether the green buildings affect its users in buying property, for example, the residential houses or apartment units. This study also aims to determine whether the green building users prioritize environmentally friendly as the main aspect of choosing their properties.

This study assumes that green buildings can nurture green users and green users over time become green buyers, although, in reality, some obstacles may exist. The social aspects of green building are not balanced with economic and environmental considerations [1]. Green building design strategies are not well communicated to the users [7]. Therefore, all of the green buildings' aspects must be successfully communicated to green users, especially the standardization of green buildings in Indonesia [8]. Building management often ignores the energy and water conservation potential offered by green features in buildings and design strategies due to a lack of knowledge [7]. This is not in line with the objectives of green buildings and has the potential to hinder users from forming and developing their behaviour in green buildings (green users). In addition, the hope that green users will eventually become green buyers has not been realized, especially in the context of choosing residential properties that prioritize environmentally friendly aspects. These research subjects are workers or middle-class employees who have worked a minimum of 1 year in the building.

Building users who have more awareness of green behaviour are needed to realize environmentally-friendly residential properties. Hence, the purpose of this research is to determine the role of green buildings in two behavioural concepts, namely the green user (green building user) and the green buyer towards their wishes and plans in choosing residential property (residential or apartment units). As a comparison, the behaviour conditions of building users who are not certified as green buildings were involved to see whether the green buyer behaviour is also formed even though the users do not carry out any activities in green buildings.

\subsection{Green building}

A green building is defined as a new, old, or newly renovated building that is certified, or plans to be certified, by an authorized green building agency, or is designed, built, maintained, or renovated in accordance with established guidelines, and will lead to sustainability [9]. In order to be categorized as green buildings, standards, or benchmarks are needed as a guide in designing and measuring the greenness level of a building or the environment [10]. Following the footsteps of several countries that have issued standardization of green buildings, Indonesia was finally formed by the Indonesian Green Building Council (GBCI) in 2009 and was registered as a member of the World Green Building Council based in Canada [10].

\subsection{Green buyer}


A green buyer is defined as someone who has an awareness of environmental care and a willingness to spend more money to be more environmentally friendly. Green buyers put environmental concern in his/her priority in buying things and are also often referred to as the green consumer.

\subsection{Green buyer behaviour}

Green behaviour can be defined as actions that involve users, relate and contribute to environmental sustainability [11]. There is a reciprocal relationship between humans and their built environment, which affects a person's behaviour and vice versa. A person's behaviour can affect the built environment [12].

In order to identify the growth of green buyer behaviour in building users, there are six constituents, including eco-literacy (understanding in interpreting environmental conditions), the emergence of awareness behaviour to reduce natural damage, engagement values, social influence, and lastly the sensitivity in buying a product. In relation to architecture, green buyer behaviour will also appear when buying and choosing residential buildings. Green buyer behaviour is driven by several factors, such as efficient use of resources, relatively lower building operating costs due to minimizing the use of air conditioning and so on, environmental conditions, distance and access to green areas, mobility, meeting buyer needs in the form of facilities, and landscapes [13].

\subsection{Green User}

In the context of this research, green users are the users of green buildings. Green users are also known as green occupants. Along with green buildings' operation, users are assumed to be motivated to carry out environmentally friendly activities, such as conserving water, reducing excess of energy use, and contributing to protecting the surrounding environment. In this study, regular building users were targeted as respondents, namely full-time workers who spend 40 hours per week in buildings. Previous studies have categorized green users' behaviour according to the type of behaviour, the level of influence, and their role in the building [11].

\section{Method}

This research uses four buildings as research objects. Some of these buildings have met GREENSHIP standards and received a Platinum, Gold, and Silver rating from GBCI. This study compares two groups of respondents who are active in different environments and buildings, so the differences can show whether the formation of sustainable behaviour is formed within these users. One hundred seventeen respondents of green building users were divided into three groups (platinum, gold, and silver rating GBCI). In comparison, 51 conventional building users were also involved in this study.

The research approach used is quantitative through the theory and the relationship of variables testing and clarifies research through comparative studies. The variables found from observations are measured using research instruments and quantified so that the data that are in the form of numbers can be analysed. The measurement instruments used in this study are the Consideration of Future Consequences (CFC) scale, parameters of "Individual Behaviour towards the Environment" (PSTL) in the form of an online questionnaire, and Green Property Brochure. 


\subsection{Consideration of future consequences (CFC) scale}

CFC scale is an instrument to measure the extent to which an individual considers and is influenced by results that are far from their current behaviour. More detailed information about CFC can be found in reference [14].

\subsection{Parameters of individual behaviour towards the environment (PSTL)}

These parameters are built based on several journals related to the criteria of building users' individual behaviour to determine whether green behaviour has been applied in everyday life. The criteria that have been collected from several related journals are then categorized according to their dimensions. Dimensions are used to make it easier to group and test the validity of each statement. The dimensions used in this study are 3R (Reduce, Reuse, and Recycle).

\subsection{The distribution of property brochures}

In this research, the distribution of property brochures is the last stage of the primary data collection. After the respondents filled out the questionnaire that had been provided, the respondents were given approximately 5 minutes to choose one of the two brochures provided. This stage aims to determine whether the respondents understand and have the desire to choose green residential properties compared to ordinary residential properties. The brochure making is based on a literature study on the factors of buying green residential properties, including 1) Efficient use of resources, 2) Low building operational cost, 3) Safe and healthy environment, 4) Access to green space, 5) Mobility, 6) Design and community planning, and 7) Landscape. Other factors were added then visualized in the forms of property brochures [15].

\section{Results and discussion}

A regression test is carried out on each building to find out whether each variable affects or not. The regression test was also then carried out on the overall questionnaire value by selecting the property brochure. This is done to determine whether the value of the questionnaire from building users affects property brochures' selection. The entire building's regression results show the regression test results between the CFC Scale and Parameters of Individual Behaviour towards the Environment (PSTL) on the selection of property brochures for the entire building shown in Table 1. Table 1 shows that the entire questionnaire's significance value consisting of the CFC Scale and PSTL with the selection of brochures is 0.009 (less than 0.05). Therefore, it can be concluded that the value of the questionnaire on all buildings that are the object of research $(\mathrm{A}, \mathrm{B}, \mathrm{C}$, and $\mathrm{D})$ tends to influence or play a role in the selection of the user's property brochure.

Table 1. Results of the questionnaire regression test (CFC Scale and PSTL) with the selection of property brochures.

\begin{tabular}{|c|c|c|c|c|}
\hline & & Brochure & Standard & Result \\
\hline \multirow{3}{*}{$\begin{array}{l}\text { Qu } \\
\text { est } \\
\text { io } \\
\text { nn }\end{array}$} & Reduce & \multirow[t]{3}{*}{0,009} & \multirow{3}{*}{$\begin{array}{c}<0.05 \text { has } \\
\text { an effect, }> \\
0.05 \text { has no } \\
\text { effect }\end{array}$} & \multirow[t]{3}{*}{ Has an effect } \\
\hline & Reuse & & & \\
\hline & Recycle & & & \\
\hline
\end{tabular}




\begin{tabular}{|c|l|l|l|l|}
\hline $\begin{array}{c}\text { air } \\
\mathrm{e}\end{array}$ & & & & \\
& CFC Scale & & & \\
& & & & \\
\hline
\end{tabular}

\subsection{Overall results of the questionnaire - cfc scale value, parameters of individual behaviour towards the environment (PTSL), and selection of brochures}

The result formulations of the questionnaire involve four buildings. Those are Building A (GREENSHIP rating Platinum), Building B (GREENSHIP rating Gold), Building C (GREENSHIP rating Silver), and Building D (conventional building). The respondents in this study are 168 respondents, 35 respondents of building A, 45 respondents of building B, 37 respondents of building $\mathrm{C}$, and 51 respondents of building $\mathrm{D}$.
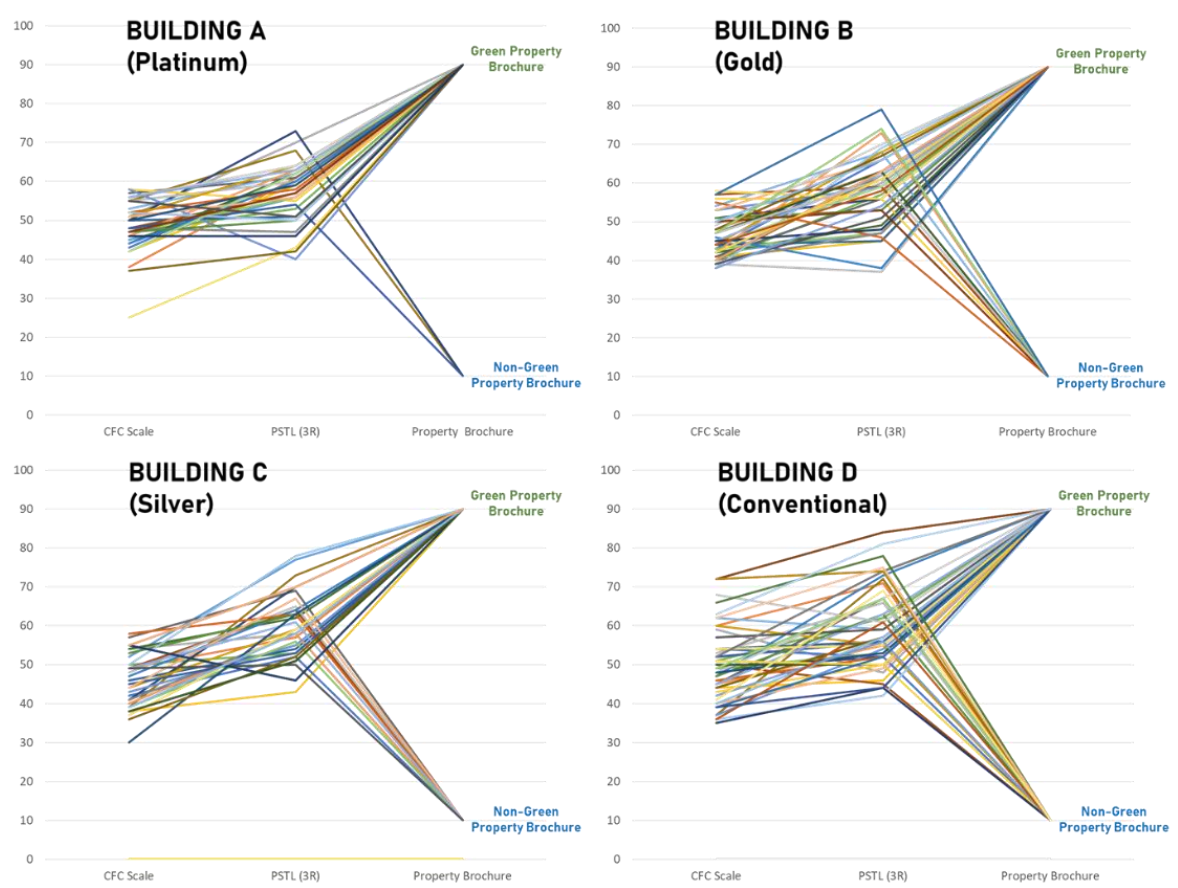

Fig. 1. Diagram of Questionnaire Results in Building A (Platinum), B (Gold), C (Silver), and D (Conventional).

The diagram of Building A shows that 3 out of 35 respondents in building A chose nongreen property brochures, while 32 other respondents preferred green property brochures (Figure 1). The diagram shows that the respondent with the lowest CFC Scale value and the one with the low PSTL value in building A chose the green property brochure. This is due to 
other factors outside of research that support users in choosing green properties. The reason respondents chose the green property brochure was because of the more attractive building facade. Other factors that motivated the other three respondents to choose non-green brochures were lower prices, mobility of private vehicles, and simpler building facades.

The diagram of Building B in Figure 1 shows that 10 out of 45 respondents in building B prefer non-green brochures, while the other 35 respondents prefer green property brochures. Several respondents had low scores in the CFC Scale and PSTL assessments but chose the green property brochure. This is probably due to other factors not included in this study. One of the respondents with a high CFC Scale score (scored 57 out of 72) and the highest PSTL (scored 79 out of 84 ) in building B prefers a non-green property brochure. The respondent chose the non-green property brochure because of the non-green building features that the respondent felt was sufficient. The driving factors for building B respondents who chose the green property brochure were the better look of the brochure layout, lower apartment unit price, and some respondents felt more suitable for facilities that were not equipped with green features.

The diagram of Building $\mathrm{C}$ above shows that 11 out of 37 respondents in building $\mathrm{C}$ chose non-green property brochures, while the other 26 respondents chose green brochures. It was found that some respondents who had a low CFC Scale (30 out of 72) but high PSTL (63 out of 84) chose green property brochures. For example, one of the respondents chose a green property brochure because of the GREENSHIP logo prominently displayed in the green property brochure. Two of the respondents chose green property brochures because of the higher percentage of green space. Several other reasons were supported by more affordable prices, more attractive building facades, and private vehicles' mobility.

Building D's diagram above shows that 17 out of 51 respondents in building C chose nongreen property brochures, while 34 other respondents chose green brochures. The reason for choosing the non-green brochure from 17 respondents on average was driven by a more affordable price, toll access, and had enough of the facilities provided by the non-green property brochure.

\subsection{Results of green and non-green property brochures}

In contrast to the questionnaire, green property brochures and online written interviews were conducted after the respondents filled out a questionnaire to determine whether someone who has high CFC and PTSL values has the desire to buy the green residential property. Selection of brochures by respondents consisting of 35 users of Building A, 45 users of building B, 37 users of Building $\mathrm{C}$, and 51 users of building D. The results of the selection of property brochures are presented in Figure 2. 


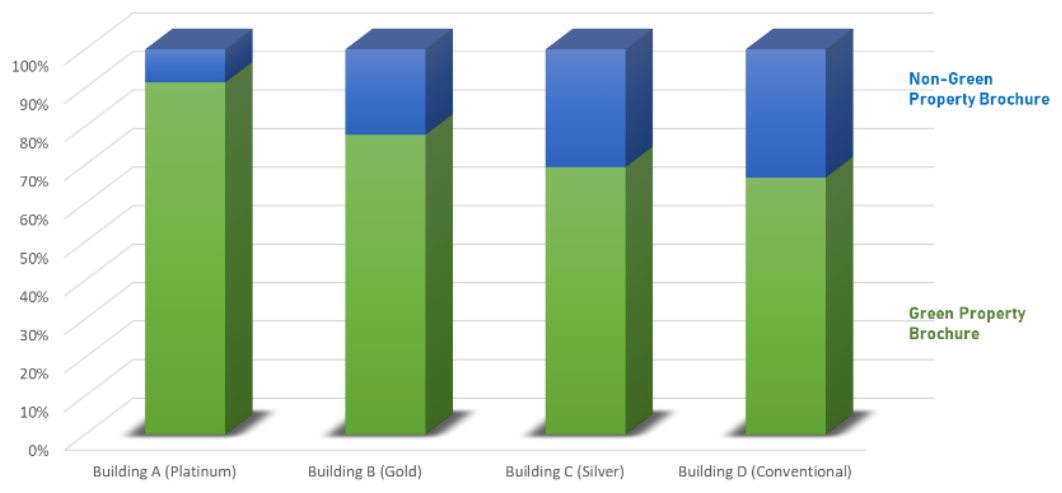

Fig. 2. Overall diagram of green and non-green property brochure selection results.

The diagram in Figure 2 shows that the percentage of building users who mostly choose the green property brochure in building A (GREENSHIP rating Platinum), reaching $91.4 \%$. Meanwhile, in building B, $78 \%$ of users choose green residential properties. Building C, $69 \%$ of the respondents who are building users choose the green property brochure. Then the percentage who chose the green property brochure in building D reached $66.7 \%$.

The percentage or building users who choose green property brochures from building A to $\mathrm{D}$ are decreased. This is due to the possibility that the existing green features of the building with the GREENSHIP rating are obtained to support its users in buying greener properties. The influence or role of green buildings on selecting property brochures is also clearly visible from the diagram Figure 3.

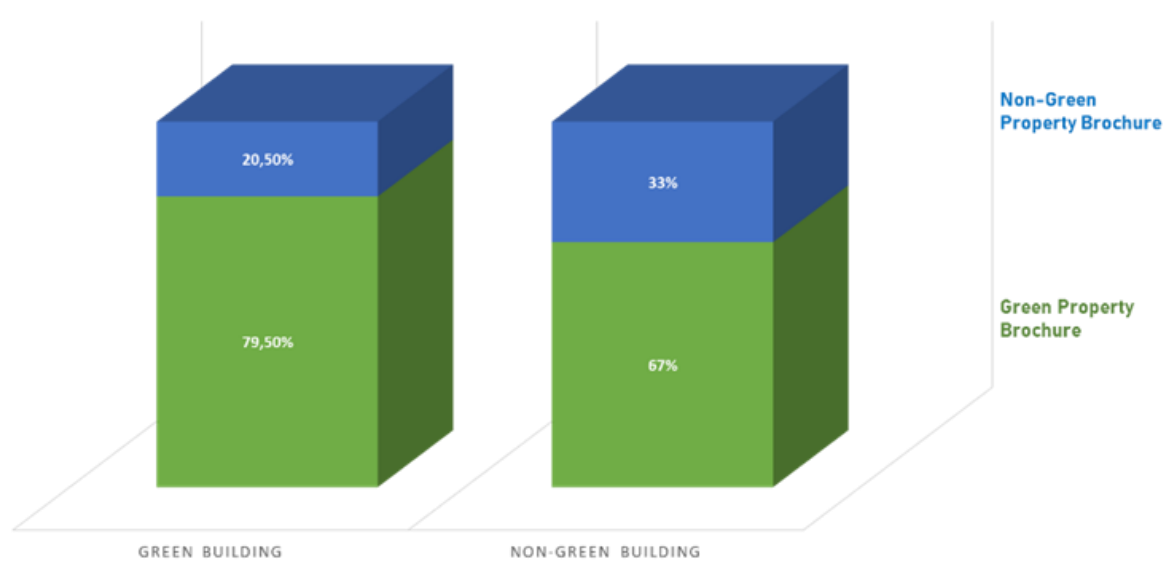

Fig. 3. Overall diagram of green and non-green property brochure selection results.

Diagram in Figure 3 shows a comparison of the selection of brochures chosen by green buildings and conventional buildings. It can be seen that users of green buildings who choose green property brochures are $79.5 \%$. Meanwhile, in conventional (non-green) buildings, $67 \%$ of respondents chose green property brochures. It can be concluded that green buildings influence users in choosing green residential properties compared to conventional buildings. After knowing how many building users in each research object chose the green property brochure, the results also show several factors driving building users in choosing the brochure they want. The results are presented in a pie chart below (Figure 4): 


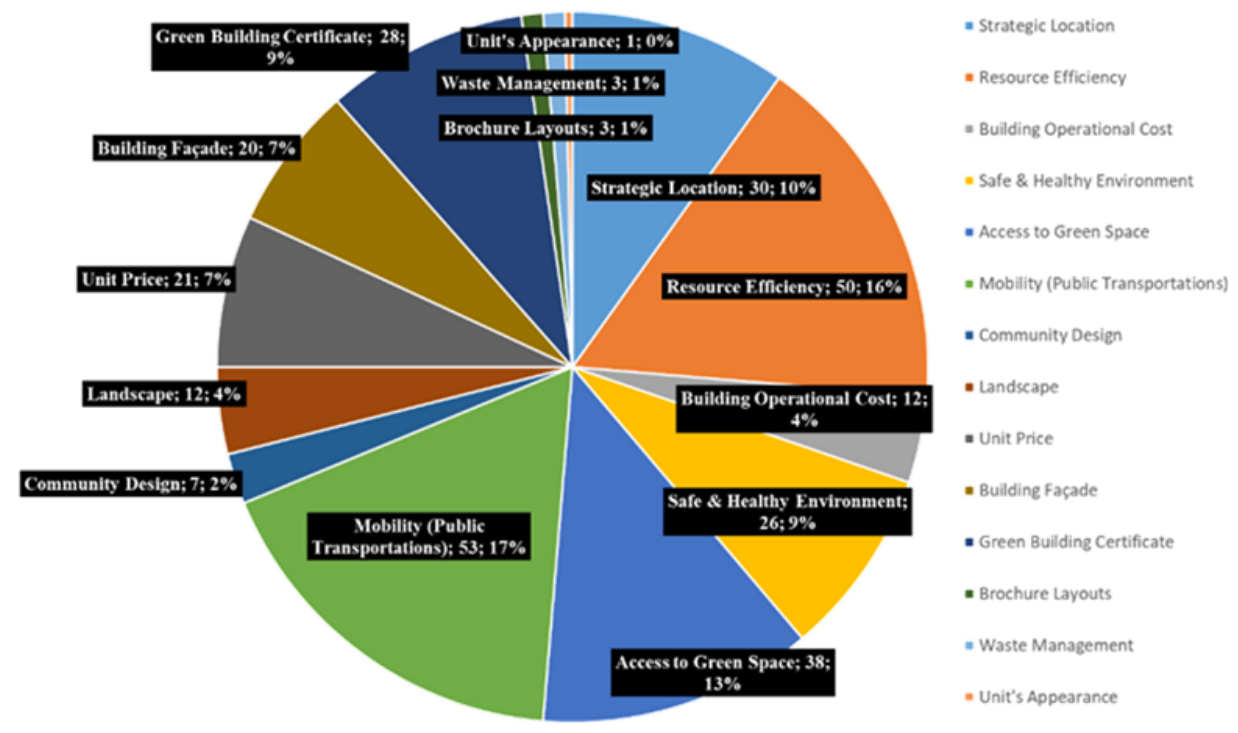

Fig. 4. Overall diagram of green and non-green property brochure selection results.

The diagram in Figure 4 shows that the main factor that supports building users in choosing the green property brochure is the mobility of public transportation around the property, especially close to MRT stations. Mobility is the main reason for 53 respondents (17\%). The second most common reason for choosing green property brochures is resource efficiency by 50 respondents $(16 \%)$. The implementation of green features such as water treatments and smart home systems makes building users consider buying green properties. The third most common factor is access to green spaces by 38 respondents (13\%). Green space in the form of a recreation area dominated by a park can attract users to choose green properties. The fourth factor is the location, which was mentioned by 30 respondents $(10 \%)$. The location of the apartment, which is relatively close to hospitals, schools, universities, and shopping centres as an attraction in choosing green properties.

\section{Conclusion}

It can be concluded that green buildings have a higher role in supporting green users and influence them in buying green residential properties compared to conventional buildings. It is proven by the percentage of users who choose the green property that seems to be decreasing, sequentially starting from Building A to Building D. It is also proven that there is significant influence between users of green buildings and the choice of green residential properties. There is also a significant influence between users of green buildings and the selection of green residential property by 0.009 .

Mobility, resource efficiency, access to green space, and strategic location are the main factors in choosing green properties. The research also found that some respondents with large CFC scale and PSTL values preferred non-green property brochures. This is because there are factors such as price and building features that are deemed sufficient. Some respondents had low scores, preferred green property brochures. This is due to the factors outside the research that might also influence it.

This research has explored whether someone who works in green buildings has ecoconscious attitudes and will be compelled to buy the green residential property. Also, this 
study also describes the main factors driving building users to choose green residential properties. In this study, what was not discussed further was the stage of changes in building users' behaviour who gradually became green buyers. This is due to the limited research time and the constraints of the situation when the COVID-19 pandemic hampers research. Therefore, further research can focus on the stage of changing user behaviour in green buildings.

\section{Acknowledgements}

This research is funded by grant research PUTI-UI Saintekes with the contract no: NKB2452/UN2.RST/HKP.05.00/2020. The authors would like to gratefully thank Dr. Dipl. Psych. Ratna Djuwita, Lecturer from Faculty of Psychology. Universitas Indonesia for all her advice and ideas during the research tool development.

\section{References}

1. Ragheb, A., El-Shimy, H., \& Ragheb, G. Green Architecture: A Concept of Sustainability. Procedia - Social and Behavioral Sciences, 216, 778-787 (2016) https://doi.org/10.1016/j.sbspro.2015.12.075

2. Kriss, Jacob. What is green building? Taken from (2014, August 6th) https://www.usgbc.org/articles/what-green-building

3. Cole, L.B. Green Building Literacy: a Framework for Advancing Green Building Education. International Journal of STEM Education, 6:18 (2019)

4. Xie, X., Lu, Y., \& Gou, Z. Green building pro-environment behaviors: Are green users also green buyers? Sustainability (Switzerland), 9(10) (2017) https://doi.org/10.3390/su9101703

5. Suki, N. M. Green Awareness Effects on Consumers' Purchasing Decision: Some Insights from Malaysia. IJAPS,9, 2, 50-63 (2013)

6. Moser, A. "Thinking green, buying green? Drivers of pro-environmental purchasing behavior", Journal of Consumer Marketing,32,3,167-175 (2015)

7. Lim, Celine. Green buildings need careful management to perform (2013) www.ecobusiness.com/news/series/international-green-building-conference-2013/

8. G.T. Ayuthia, O.C. Dewi, T.H. Panjaitan. Green User and Green Buyer as Supporters for the Achievement of Green Buildings: A Review. Proceedings of the 3rd International Conference on Dwelling Form (IDWELL 2020) (2020) https://doi.org/10.2991/assehr.k.201009.004

9. Susie Ruqun Wu, Suk Kyung Kim et al. How do Green Buildings Communicate Green Design to Building Users? A Survey Study of a LEED-Certified Building. Journal of Green Building, 12, 3, 6 (2017)

10. Nugroho, A. C. Sertifikasi Arsitektur Bangunan Hijau: Menuju Bangunan yang Ramah Lingkungan. Jurnal Arsitektur Universitas Bandar Lampung,2,1,12-22 (2011)

11. Ones, Deniz \& Dilchert, S. Employee green behaviors. Managing HR for environmental sustainability. 85-116 (2012)

12. McClure, W. R., \& Bartuska, T. J. The Built Environment: a Collaborative Inquiry into Design and Planning. Somerset: Wiley (2011)

13. Ismail, R., Shafiei, M. W. M., Said, I., \& Ibrahim, F. A. Green Homes Development Practices and House Buyers' Requirements: A Review. Aust. J. Basic Appl. Sci., 7(13), 7-15 (2013) 
14. David R. Rappange, Werner B.F. Brouwer \& N. Job A. van Exel. Back to the Consideration of Future Consequences Scale: Time to Reconsider?, The Journal of Social Psychology, 149:5, 562-584 (2009)

15. G.T. Ayuthia, O.C. Dewi, T.H. Panjaitan. "Green Property Brochure: Do Green Users prefer Green Residentials?" Proceeding, The 5th International Engineering Student Conference (IESC) (2020) 